\title{
Opal-RT based Analysis and Implementation of Single Phase Cascaded Multilevel Inverter with Minimum Number of Switches
}

\author{
Abeera Dutt Roy* and Chandrahasan Umayal \\ School of Electrical Engineering, VIT University, Chennai - 600127, Tamil Nadu, India; \\ abeera.duttroy2013@vit.ac.in
}

\begin{abstract}
Objective: In this paper, the detailed analysis and performance of a single phase multilevel inverter topology is dicussed in order to produce a high quality of output voltage. Method: A seven level cascaded inverter topology having six switches is utilized to reduce the total harmonic distortion and the switching losses. This in turn reduces the overall cost of the system. The comparison between the proposed architecture and the existing architectures is done based on the power switches, DC voltage at the inputs, the number of clamping diodes and capacitors used. It is observed that the switch count is halved. Findings: Evaluation is done using phase disposition multicarrier pulse width modulation technique where all the carriers are in phase. Thus this technique is found to be capable of achieving minimum harmonic voltage distortion, thereby resulting in a nearly sinusoidal waveform. Improvements: The performance of the suggested topology is validated in real time environment using Opal-RT Lab simulator and adequate results were taken. The results obtained proved that by using lesser number of switches there is reduction in harmonic voltage distortion in comparison with the traditional multilevel inverter topologies.
\end{abstract}

Keywords: Cascaded Multilevel Inverter, Multicarrier Pulse Width Modulation, Opal-RT, Sinusoidal Waveform, Total Harmonic Distortion

\section{Introduction}

In the recent times, multilevel inverters (MLI) have been increasingly used for high-voltage and high-power applications. Basically MLI deals with the utilization of higher number of semiconductor switches to achieve a nearly sinusoidal output voltage. There are various advantages of MLI like lesser output harmonics leading to good power quality, low switching losses and lower commutation losses. But their major shortcoming lies in the utilization of a greater number of devices, use of passive components and the difficulty in balancing the capacitor voltage. When the number of voltage levels rises, the requirement of the DC sources increases and this leads to increased cost and the overall complexity of the system also surges ${ }^{1-10}$.

The fundamental MLI topologies reported in various literature are cascaded H-bridgen, flying capacitor and diode-clamped converter ${ }^{13}$. In comparison with all these topologies, the cascaded MLI have drawn much attention because it enjoys the benefits of modularized layout and modified voltage levels by adding full bridge structures ${ }^{14,15,16}$. The cascaded MLI is divided into two types as symmetrical and asymmetrical. When the DC voltage sources are provided with identical values, it is referred to as symmetric else it is termed as asymmetric. The advanage of the asymmetrical multilevel inverters lies in its capability to generate greater number of output voltage levels while using the same number of power electronic components 1 . In the recent times, many architectures of the cascaded multilevel inverters using reduced switch count are reported ${ }^{18,11}$. These topologies utilize minimum number of switches and are also able to generate all possible levels of even and odd voltages. Various algorithms which are used to measure the magnitudes of the input DC voltage sources have been reported 20-22. Another variance of MLI are referred as modular multilevel converters where the DC voltage

${ }^{*}$ Author for correspondence 
sources are replaced by capacitors which are charged with the help of redundant switching combinations ${ }^{3,24}$. The topology discussed in this paper requires a sub multilevel cell with many DC voltage sources of equal magnitude which helps to generate the output voltage. Both symmetric and asymmetric variations of this

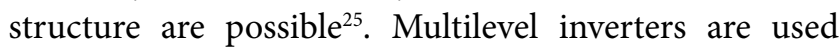
in various fields like flexible AC transmission systems, different drives and devices used in renewable energy systems?

The multilevel inverter proposed in this paper is capable of generating greater number of output voltage levels by using lesser number of components. The comparison between the proposed topology and the conventional topologies are performed on the basis of switch counts, DC power sources, number of clamping diodes and capacitors. The performance of the suggested topology was affirmed using Opal-RT Lab simulator. Comparing the results with that of conventional topologies, it is found that the same number of voltage levels are obtained with lesser number of switches.

\section{Proposed Topology}

Figure 1 shows the arrangement of the proposed topology which includes a fundamental module and a $\mathrm{H}$ bridge structure. This module is made up of ' $n$ ' bidirectional switches and the number of DC voltage sources used is given as ' $n+1$ '. In this architecture, common emitter configuration is used for the bidirectional switches where the combination of an anti parallel diode and an IGBT are utilized to form a switch. The advantage of this configuration lies in the usage of a single gate driver circuit which has the ability of obstructing the voltage and allowing the current to flow in both the directions. The full bridge converter consists of unidirectional switches which includes an IGBT and an anti-parallel diode ${ }^{2}$.

Table 1. Switching states of the proposed topology

\begin{tabular}{ccccccc}
\hline $\mathrm{S}_{1}$ & $\mathrm{~S}_{2}$ & $\mathrm{~S}_{3}$ & $\mathrm{~S}_{4}$ & $\mathrm{~S}_{5}$ & $\mathrm{~S}_{6}$ & $\mathrm{~V}_{0}$ \\
\hline 0 & 0 & 1 & 0 & 0 & 1 & $\mathrm{~V}_{1}$ \\
0 & 1 & 0 & 0 & 0 & 1 & $\mathrm{~V}_{2}$ \\
1 & 0 & 0 & 0 & 0 & 1 & $\mathrm{~V}_{1-} \mathrm{V}_{2}$ \\
0 & 0 & 0 & 1 & 0 & 1 & 0 \\
0 & 1 & 0 & 0 & 1 & 0 & $-\mathrm{V}_{1}$ \\
0 & 1 & 1 & 0 & 1 & 0 & $-\mathrm{V}_{2}$ \\
0 & 0 & 0 & 1 & 1 & 0 & $-\left(\mathrm{V}_{1}, \mathrm{~V}_{2}\right)$ \\
\hline
\end{tabular}

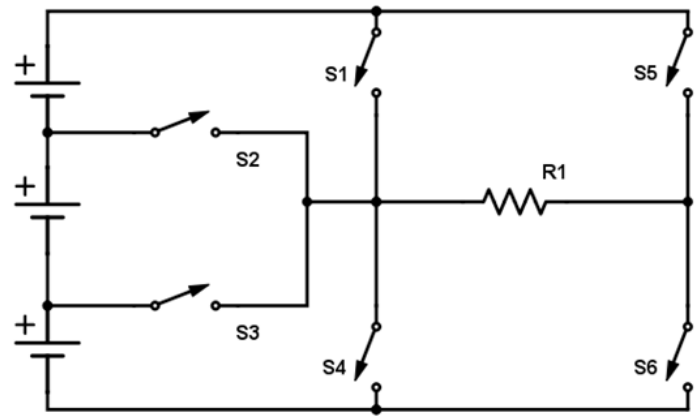

Figure 1. Proposed Multilevel Inverter Topology.

The switching states of the topology are shown in Table 1 where ' 1 ' and ' 0 ' denotes the ON state and OFF state of the switches respectively.

Table 2 shows a detailed comparison of the switches and the sources required in the case of seven level topology. It is noticed that the number of switches used in this topology is reduced up to $50 \%$ in comparison with the traditional architectures.

Table 2. Comparison between the proposed and existing topologies for 7 levels 肺

\begin{tabular}{lcccc}
\hline Parameters & $\begin{array}{c}\text { Cascaded } \\
\text { H bridge }\end{array}$ & $\begin{array}{c}\text { Diode } \\
\text { Clamped }\end{array}$ & $\begin{array}{c}\text { Flying Ca- } \\
\text { pacitor }\end{array}$ & $\begin{array}{c}\text { Proposed } \\
\text { Topology }\end{array}$ \\
\hline Main Switches & 12 & 12 & 12 & 6 \\
$\begin{array}{l}\text { Bypass Diodes } \\
\text { Clamping }\end{array}$ & - & - & - & - \\
diodes & - & 30 & - & - \\
$\begin{array}{l}\text { DC split Ca- } \\
\text { pacitors }\end{array}$ & - & 3 & 3 & - \\
$\begin{array}{l}\text { Clamping } \\
\text { capacitors }\end{array}$ & - & - & 15 & - \\
DC sources & $\mathrm{N}$ & 1 & 1 & 3 \\
\hline
\end{tabular}

Table 3 shown below highlights the comparison of the proposed topology with the cascaded structure in terms of the power electronic components utilized for different levels. This helps to put forward the advantages and the improvements created and echoes the superiority of the proposed archetype.

Table 3. Comparison in terms of power electronic components used for different voltage levels

\begin{tabular}{lcccc}
\hline $\begin{array}{l}\text { No of } \\
\text { levels }\end{array}$ & $\begin{array}{c}\text { No of Power electronic } \\
\text { switches }\end{array}$ & \multicolumn{2}{c}{ No of DC sources } \\
\hline 7 & Proposed & Cascaded & Proposed & Cascaded \\
& 6 & 8 & 3 & 3 \\
9 & 7 & 16 & 4 & 4 \\
11 & 8 & 20 & 5 & 5 \\
\hline
\end{tabular}


The behavior of each level of the seven level inverter along with the positive and the negative half cycles is illustrated in the Figures 2-5. The output voltage levels are given by $2 n+1$, where $n$ is the number of DC voltage sources.

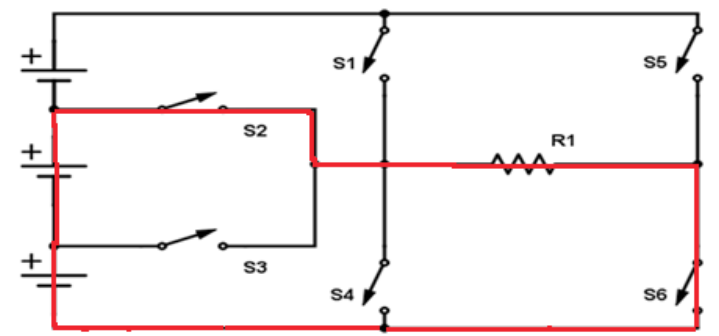

Figure 2. Mode 1.

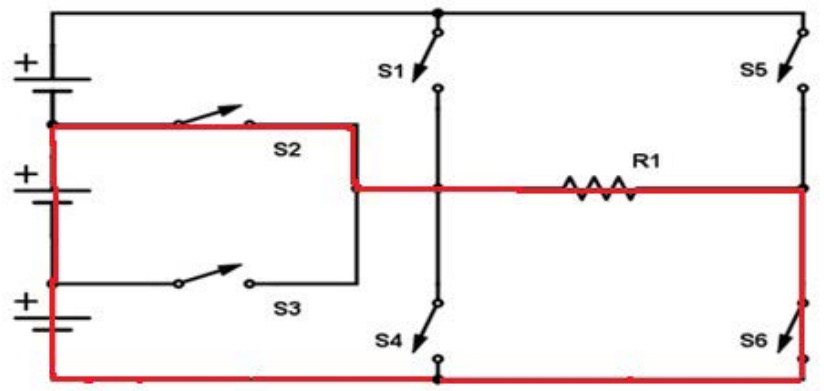

Figure 3. Mode 2.

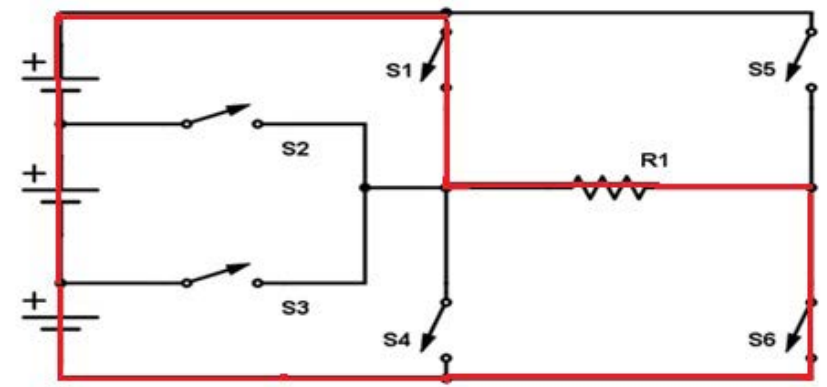

Figure 4. Mode 3.

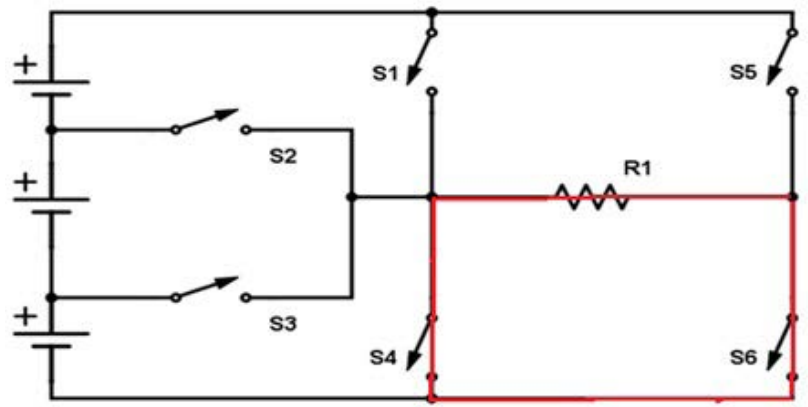

Figure 5. Mode 4.

\section{Real Time Simulation Results}

The RT-Lab simulator the brain child of Opal-RT Technologies is used as the the real time simulation environment to simulate the proposed multilevel inverter topology $y^{8,29}$, The MATLAB/Simulink models were developed and these models were then interfaced with the Opal-RT simulator through the ethernet as shown in Figure 6. The voltages are chosen as V1 $=100 \mathrm{~V}, \mathrm{~V} 2=100 \mathrm{~V}$ and $\mathrm{V} 3=100 \mathrm{~V}$ in order to obtain seven levels across a RL load with the values of $\mathrm{R}$ as $100 \Omega$ and $\mathrm{L}$ as $100 \mathrm{mH}$. It uses a multi carrier pulse width modulation technique with a carrier frequency of $2 \mathrm{kHz}$. In this technique of generating seven voltage levels, six carrier waveforms are required.
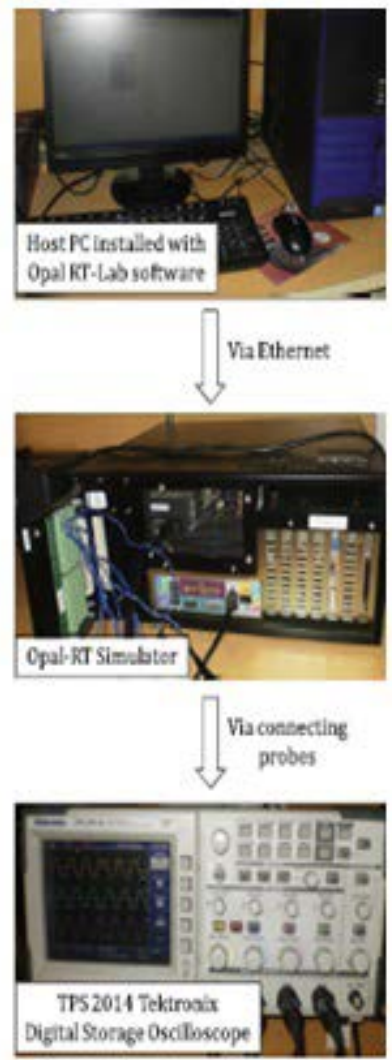

Figure 6. Experimental setup of the Opal-RT Lab.

The maximum voltage stress present across various power switches is depicted in Figure 7. 
Figures 8 and 9 show the output voltage along with the inductive load current which is free from distortion due to the modulation technique used.
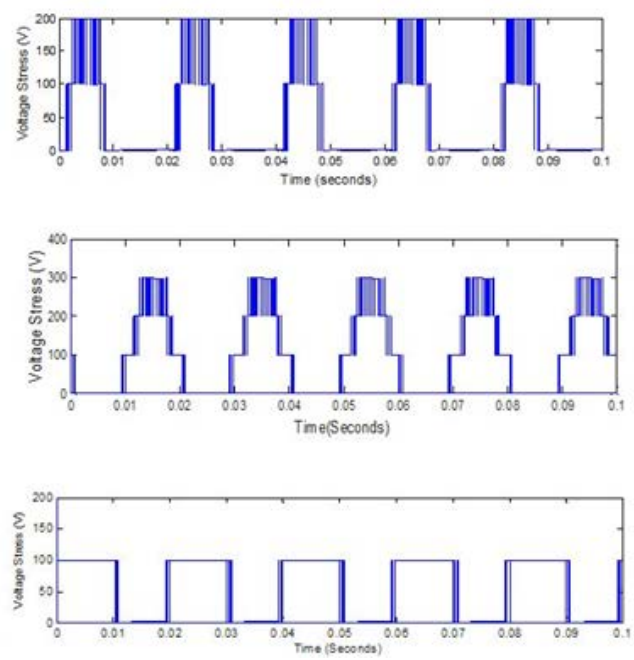

Figure 7. Maximum blocking voltage profile of the power switches of the proposed topology.

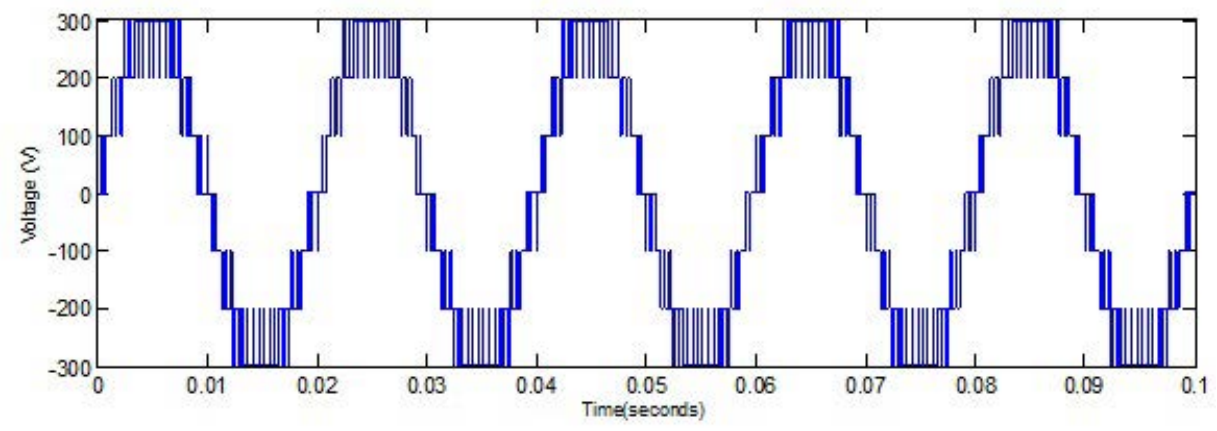

Figure 8. Output Voltage of the Proposed Topology.

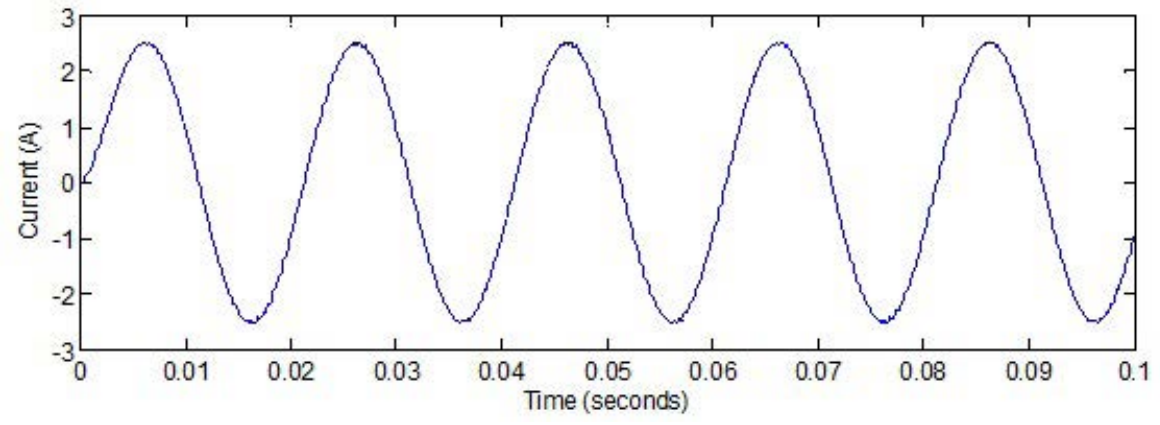

Figure 9. Load Current of Proposed. 


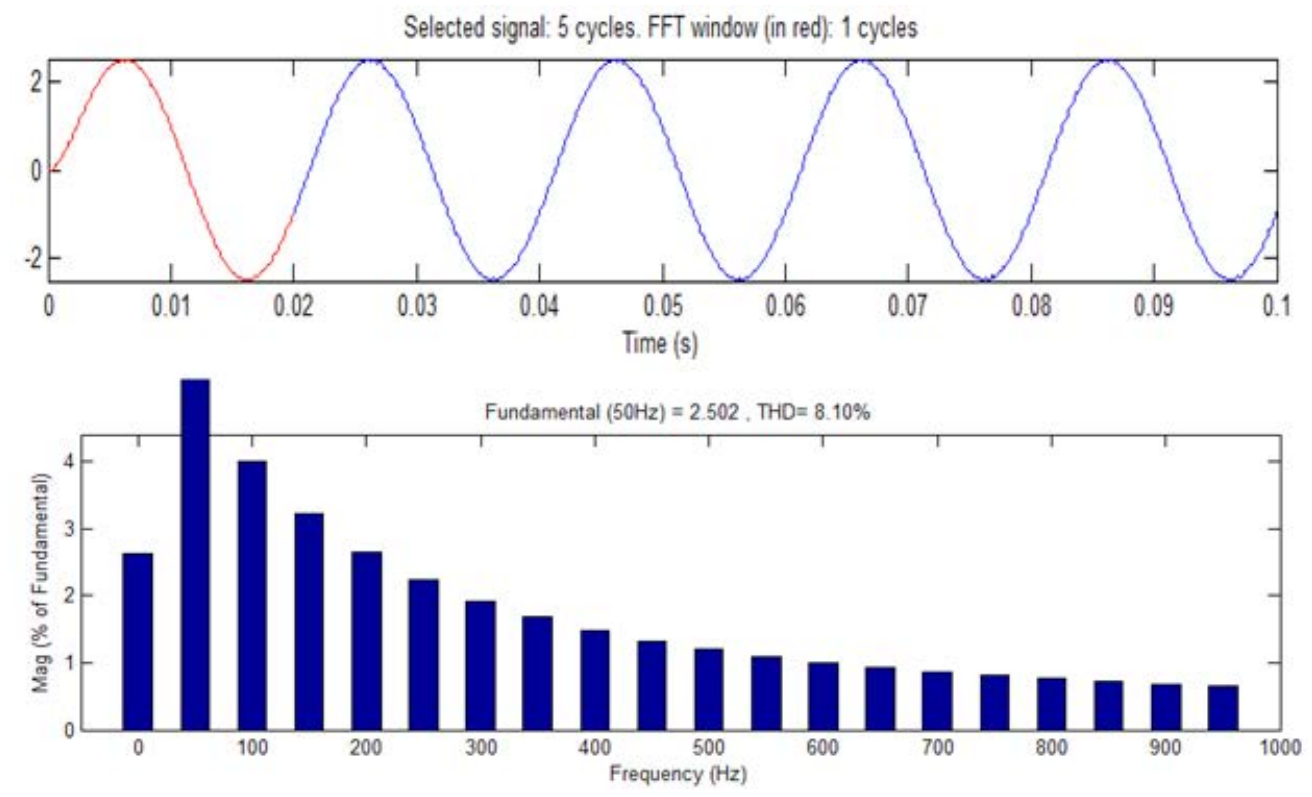

Figure 10. Harmonic profile of the Proposed Topology.

\section{Conclusion}

In this paper, a single phase multilevel inverter has been proposed with reduced power semiconductor devices. And the switch count is decreased upto $50 \%$ in comparison with the conventional cascaded multilevel inverter topology. This aids in reducing the size and the cost of the gate driving circuits. It adopts the multi carrier pulse width modulation methodology to produce the output voltage and current thereby reducing the THD significantly. Its validation is verified by using OPAL-RT simulator which helps in obtaining real time results and thus proves the viability of the mentioned topology.

\section{References}

1. Shobanadevi N, Krishnamurty V, Stalin N .PISB Control of Single Phase QuasiImpedance Source DC-DC Converter Indian Journal of Science and Technology.2015 July; 8(13):1-10.

2. Rodriguez J, Lai JS, Peng FZ. Multilevel inverters: a survey of topologies, controls, and applications. , IEEE Trans on Indust Electronics. 2002; 49(4):724-38.

3. Rasheed M, Omar R, Sabari A, Sulaiman M. Validation of a Three-Phase Cascaded Multilevel Inverter based on Newton Raphson (N.R.),Indian Journal of Science and Technology.2016 May; 9(20):1-13.

4. Lai JS, Peng FZ. Multilevel converters - a new breed of power converters. IEEE Transformation and Industrial Applied .1996;32(3):509-17.
5. Mohammed Rasheed, Rosli Omar, Afiqah Sabari, Marizan Sulaiman,Validation of a Three-Phase Cascaded Multilevel Inverter based on Newton Raphson (N.R.),Indian Journal of Science and Technology.2016 May:9(20).DOI no:10.17485/ijst/2016/v9i20/89357.

6. Yamini K,Vasudha B, Avinash Sharma, P. Ponnambalam. Implementation of Fuzzy Logic Controller for Cascaded Multilevel Inverter with Reduced Number of Components,Indian Journal of Science and Technology,2015 Jan: 8(S2).DOI no: 10.17485/ijst/2015/v8iS2/71717.

7. Siddartha K. A.,Manikanta Babu N, Suresh Y,Varun Mohan M. Enhanced Performance of a DVR using Mixed Cascaded Multilevel Inverter,Indian Journal of Science and Technology,2015 Jan:8(S2). DOI no: 10.17485/ijst/2015/ v8iS2/60445.

8. Elavarasi R, SenthilKumar P. K. An FPGA Based Regenerative Braking System of Electric Vehicle Driven by BLDC Motor,Indian Journal of Science and Technology,2014 Nov:7(S7). DOI no:10.17485/ijst/2014/v7iS7/60170.

9. Shivani Pasricha, Sanjay Sharma. FPGA Based Design of Reed Solomon Codes,Indian Journal of Science and Technology,2009 Apr, 2(4), Doi no: 10.17485/ijst/2009/ v2i4/29431.

10. De S, Banerjee D, Sivakumar K, Gopakumar K, Ramchand $\mathrm{R}$, Patel C. Multilevel inverters for low-power application. IET Power Electron.2011; 4(4):384-92.

11. Ebrahimi J, Babaei E, Gharehpetian GB. A New Multilevel Converter Topology With Reduced Number of Power Electronic Components. IEEE Transactions on Industrial Electronics.2012;59(2):655-67.

12. Marchesoni M, Mazzucchelli M, Tenconi S. A non conventional power converter for plasma stabilization. In Proceedinngs Power Electronics Specalist. Conjucation.1988.p.122-29. 
13. Meynard TA,Foch H. Multi-level choppers for high voltage applications. In Proceedings. European Congress Power Electronics Applied.1992;2(1):45-50.

14. Nabae A, Takahashi I, Akagi H. A new neutral-point clamped PWM inverter.IEEE Transformation . Indian Applied.1981; IA-17( 5):518-23.

15. Babaei E. A cascade multilevel converter topology with reduced number of switches. IEEE Transfomation. Power Electronics .2008;23(6):2657-664.

16. Ebrahimi J, Babaei E, Gharehpetian GB. A New Topology of Cascaded MultilevelConverters With Reduced Number of Components for High-Voltage Applications. IEEE Transactions on Power Electronics.2011;26(11):3109-118.

17. Mekhilef S,Kadir MN. Novel vector control method for three-stage hybrid cascaded multilevel inverter.IEEE Transformation. Indian Electronics. 2011;58(4):1339-349.

18. Babaei E, Moeinian MS. Asymmetric cascaded multilevel inverter with charge balance control of a low resolution symmetric subsystem.Elsevier Journal of Energy Conversion and Management.2010;51(11):2272-278.

19. Babaei E, Hosseini SH, Gharehpetian GB, Tarafdar HM and Sabahi M.Reduction of dc voltage sources and switches in asymmetrical multilevel converters using a novel topology.Elsevier Journal of Electric Power Systems Research. 2007;77(8):1073-85.

20. Babaei E, Hosseini SH.New cascaded multilevel inverter topology with minimum number of switches. Elsevier Journal of Energy Conversion and Management.2009;50(11):2761-767.

21. Babaei E, Hosseini SH.New multilevel converter topology with minimum number of gate driver circuits. In
Proceedings.Power Electronics, Electrical Drives, Automation and Motion, SPEEDAM International Symposium.2008.p.792-97.

22. Hinago Y, Koizumi HA. Single-Phase Multilevel Inverter Using Switched Series/Parallel DC Voltage Sources.IEEE Trans on Indust Electronic.2010;57(8):2643-650.

23. Lesnicar A, Marquardt R.An innovative modular multilevel inverter topology suitable for a wide power range. In Proceedings.IEEE Power Technology Conference Proceedings. Sweden ;2003.p.1-6.

24. Marquardt R, Lesnicar A.A new modular voltage source inverter topology. In Proceeding .European Power Electronics (EPE) Conference.Japan;2003.

25. Babaei E, Farhadi KM, Sabahi M, Alizadeh MRP.Cascaded multilevel inverter using sub-multilevel cells.Electronic . Power Systematic. Resource.2013;96(1):101-10.

26. Mosazadeh SY, Fathi SH, Radmanesh H. New high frequency switching method of cascaded multilevel inverters in PV application.In Proceeding.Power Engineering and Renewable Energy (ICPERE).2012. p.1 - 6 .

27. Shalchi AR, Nazarpour D, . Hosseini SH, Sabahi M.Novel multilevel inverter topologies for medium and high-voltage applications with lower values of blocked voltage by switches .IET Power Electronics.2014;7(12):3062-71.

28. Panda AK, Patnaik SS.Analysis of cascaded multilevel inverters for active harmonic filtering.International Journal of Electrical Power \& Energy Systems.2015;66(1):216-26.

29. RT-Lab Professional. Available from: http://www.opalrt.com/product/rt-lab-professional. Date accessed: $1 / 10 / 2014$. 